\title{
Barite Cathodoluminescence as a Potential Indicator of Undiscovered Ore Deposits
}

\author{
Heather Lowers ${ }^{1 *}$, Danielle Olinger ${ }^{1}$ and David Adams ${ }^{1}$ \\ 1. U.S. Geological Survey, Geology, Geophysics, and Geochemistry Science Center, Denver, CO, USA. \\ * Corresponding author: hlowers@usgs.gov
}

Barite $\left(\mathrm{BaSO}_{4}\right)$ forms in diverse geologic environments of sedimentary, metamorphic, and igneous origins. Substitution of $\mathrm{Ba}$ by $\mathrm{K}, \mathrm{Ra}, \mathrm{Sr}, \mathrm{REE}, \mathrm{Fe}, \mathrm{Cu}, \mathrm{Zn}, \mathrm{Ag}, \mathrm{Ni}, \mathrm{Ra}, \mathrm{Hg}$, and $\mathrm{V}$ have been reported [1]. Laser induced luminescence in barite has been attributed to substitutions of $\mathrm{Ag}^{+}, \mathrm{Bi}^{2+}, \mathrm{Bi}^{3+}, \mathrm{Eu}^{2+}$, $\mathrm{Ce}^{3+}, \mathrm{Nd}^{+}$, and $(\mathrm{UO} 2)^{2+}[2]$. Given the presence of barite as a gangue in many types of economic mineral deposits and its ability to incorporate other cations, it was investigated as a potential indicator mineral for undiscovered ore deposits. Barite from two carbonatite-hosted REE deposits (Bear Lodge and Mountain Pass), a volcano massive sulfide deposit (Cap), and a Mississippi Valley Type deposit (Cornwallis) were characterized to determine if cathodoluminescence (CL) could differentiate deposit model types.

Polished sections of all samples were coated with approximately $20 \mathrm{~nm}$ of carbon. Target areas representing different generations of barite growth were selected by backscattered electron imagery. Simultaneous spectral CL and element maps were acquired on a JEOL 8530F Plus operated at $20 \mathrm{kv}$, $50 \mathrm{nA}$ (cup), $1 \mathrm{um} \mathrm{step,} \mathrm{and} 80$ to $100 \mathrm{~ms}$ dwell. Data were collected and processed with the xCLent software. Scatter plots of element intensities or RGB channels were used to select all barite pixels in the dataset to create a sum CL spectra of barite (Figure 1). A JEOL 8900 operated at $20 \mathrm{kv}$ and $50 \mathrm{nA}$ (cup) were used to collect element concentrations for $\mathrm{Mg}, \mathrm{S}, \mathrm{K}, \mathrm{Ca}, \mathrm{Sr}, \mathrm{Ba}, \mathrm{Ce}$, and $\mathrm{Pb}$ with the count times for each element were optimized to lower detection limits. A precipitated barite standard spiked with a range of trace element concentrations is under development for future laser ablation inductively coupled plasma mass spectroscopy analysis.

The sum spectra of barite analysed to date is shown in Figure 2. There are many similar features among the spectra, particularly between $2.5-5.0 \mathrm{eV}$ with slight differences at approximately $3.25 \mathrm{eV}$. The spectra differ most in the region less than $2.5 \mathrm{eV}$. It is notable that both the carbonatite samples have similar features at approximately $1.5 \mathrm{eV}$. To date, elemental compositions by EPMA have only been acquired from carbonatite samples where Ce $(500-2000 \mathrm{ppm}), \mathrm{Sr}(500-50,000 \mathrm{ppm})$ and $\mathrm{Ca}$ $(<50-300 \mathrm{ppm})$ have been detected. $\mathrm{Pb}(200 \mathrm{ppm}), \mathrm{Mg}(100 \mathrm{ppm})$, and $\mathrm{K}(40 \mathrm{ppm})$ were below detection for all analyses. LA-ICP-MS is planned to determine the trace element distribution of barite from numerous deposit types. The limited data collected thus far suggests further investigation of trace element concentrations and CL spectra of barite from different economic mineral deposits is warranted.

References:

[1] JS Hanor, Reviews in Mineralogy and Geochemistry 40 (2000), p. 193.

[2] M Gaft, R Reisfeld and G Panczer in "Luminescence Spectroscopy of Minerals and Materials", (Springer, Berlin Heidelberg). 


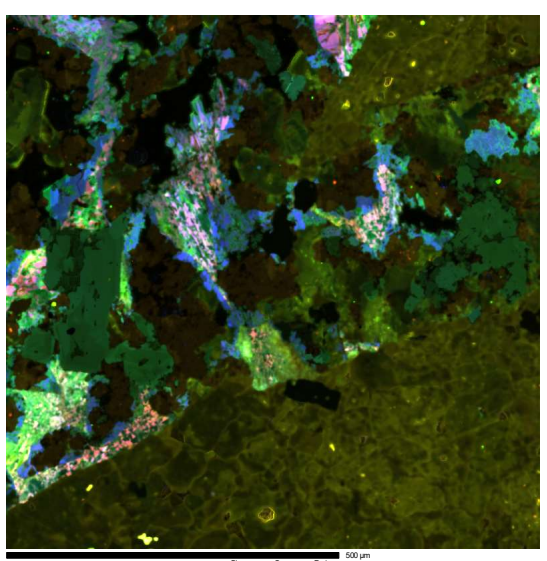

IE II
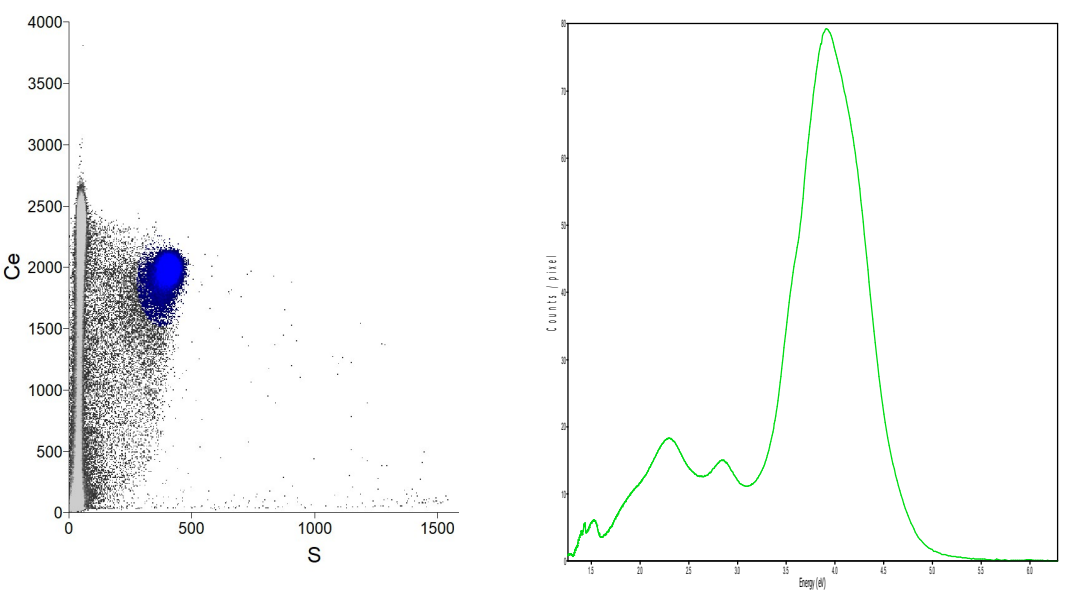

Figure 1. Left to right: Red, blue, green CL image of an area from a Bear Lodge section (scale bar is $500 \mu \mathrm{m}$ ); scatter plot of $\mathrm{Ce}$ and $\mathrm{S}$ intensities used to select barite pixels from the dataset; sum CL spectra of barite from the area shown on the left.

\section{Sum CL Spectra}

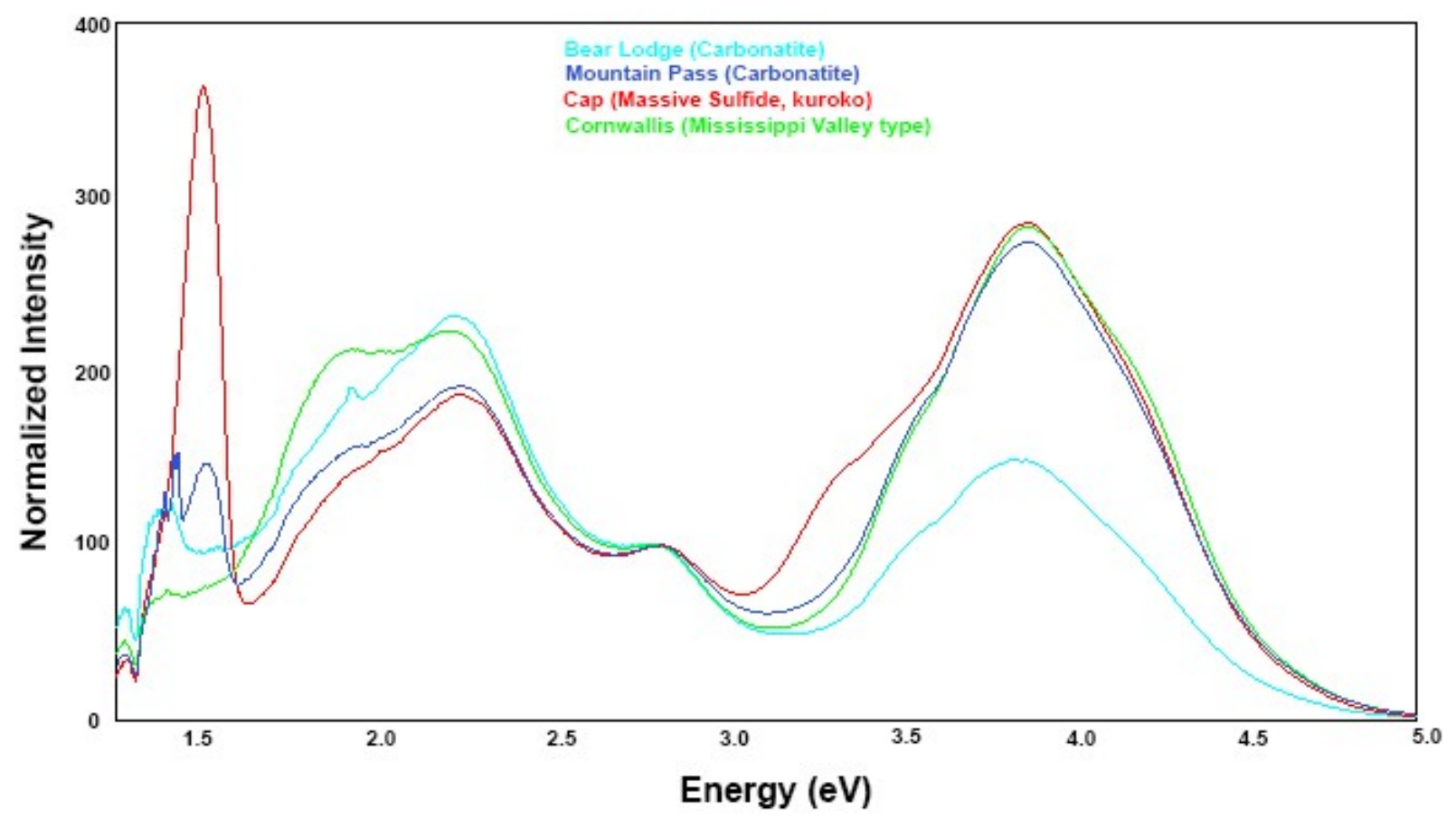

Figure 2. Sum CL spectra of barite from Bear Lodge and Mountain Pass carbonatites, Cap massive sulfide deposit, and Cornwallis Mississippi Valley type deposit. Similarities and differences are noted among the spectra. 